\title{
Desvendando patricianas máscaras
}

\author{
Maria João Brilhante
}

\begin{abstract}
Armando Nascimento Rosa, As máscaras nigromantes: Uma leitura do teatro escrito de António Patrício, Lisboa, Assírio \&t Alvim, 2004, 584 pp.
\end{abstract}

Armando Nascimento Rosa prossegue com este trabalho a divulgação da obra de importantes dramaturgos (Beckett, Natália Correia), oferecendo-nos estudos reveladores da singularidade das suas respectivas escritas e convidando os leitores a revisitá-las através de conceitos e perspectivas que as iluminam. Não pretendo, neste breve espaço, descrever exaustivamente este interessante estudo, mas sim mostrar como está estruturado e quais os aspectos que me parecem vir transformar a visão tradicional do teatro de António Patrício.

Destacarei de entre os inúmeros aspectos nele abordados uma questão tantas vezes evocada, mas tão raramente analisada nos estudos dedicados a este autor. Refiro-me à questão da dimensão teatral da escrita dramática de António Patrício.

0 título deste estudo constitui desde logo uma pista lançada ao leitor. Remete para o universo simbólico e arquetípico através das metáforas da nigromância (arte de adivinhar pela evocação dos mortos) e da máscara (indiciadora da alteridade do drama), o que suscita, aliás, a Armando Rosa a magnífica definição do dramaturgo como nigromante que cativou os fantasmas das suas criações na letra do texto. Além disso, o título circunscreve o objecto de estudo ao teatro escrito o que mostra a intenção de, por um lado afirmar o carácter gerador do "paradigma teatral", por outro de se fixar na dimensão estética e poética do drama para abordar a produção escrita e não a realização teatral dos textos de António Patrício. Trata-se de um estudo sobre literatura dramática que todavia revela sensibilidade e preocupação com a teatralidade virtual, ou, melhor dizendo, com uma ideia de teatro inscrita na letra dos textos, como creio ter entendido.

A afirmação em preâmbulo de que este estudo pretende também "aferir a especificidade do texto literário dramático através da sua intencionalidade cénica intrínseca" é francamente estimulante, se bem que constitua desígnio que transcende as possibilidades de uma investigação em torno da obra de um único autor e que, além do mais, se apresenta com o central propósito de interpretar essa obra com vista à descoberta da sua singularidade no momento histórico que a viu nascer. Na conclusão, Armando Rosa irá reunir de qualquer modo, alguns dos fios que foi identificando ao longo da análise com vista à caracterização teatral dos textos de António Patrício e dai decorre uma concepção dessa pretensa especificidade.

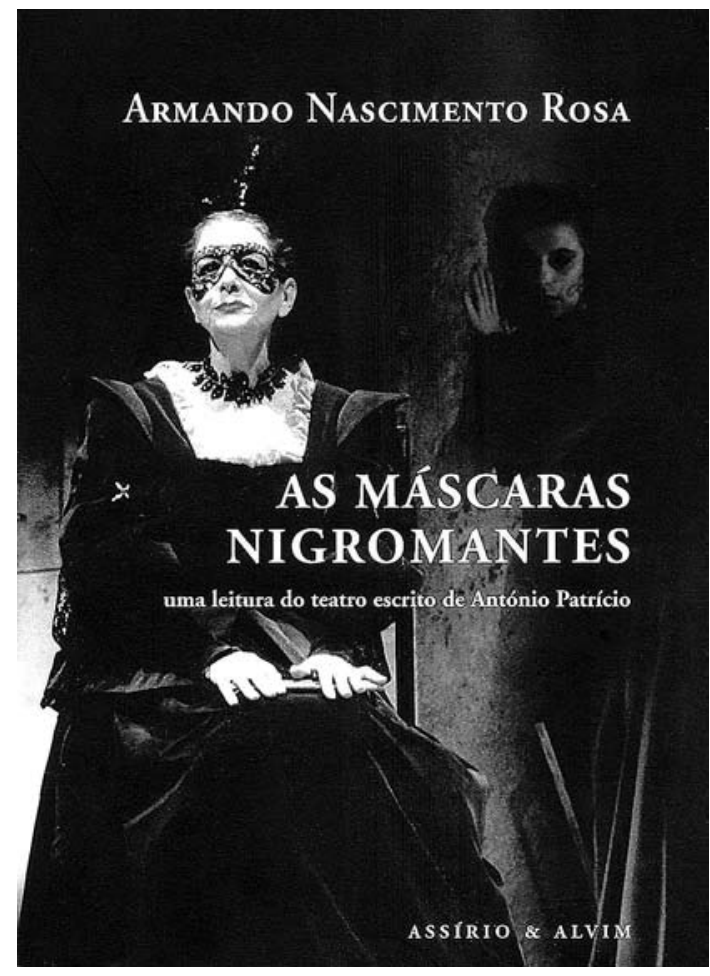

0 estudo, que constituiu uma dissertação de doutoramento, apresenta-se estruturado em três partes, correspondendo a três momentos e/ou orientações temáticas detectadas na obra e que Armando Rosa intitulou "Fascínio pelos bárbaros", "Saudade de Orfeu", "Apoteose de Eros fúnebre"; contém ainda uma extensa mas indispensável introdução, que situa a obra (e o leitor) relativamente aos modelos estéticos com os quais a escrita de Patrício se cruza, e uma conclusão, concisa se tivermos em conta a dimensão do estudo e o seu detalhe analítico. Merece ainda destaque uma bibliografia reveladora dos universos teóricos e críticos que sustentam o exercício hermenêutico de Armando Rosa e uma bibliografia secundária especifica através da qual se percebe a desatenção votada ao escritor António Patrício. No primeiro caso, note-se a amplitude das áreas do saber convocadas (filosofia, mito, religião, história literária, teoria do teatro), do diálogo entre textos e, por conseguinte, a dimensão heuristica que Armando Rosa reivindica para o seu trabalho. No segundo caso, aproveite-se o excelente balanço dos (escassos) estudos patricianos produzidos até esta data. 
A Introdução percorre de uma forma dirigida, isto é, privilegiando as questões da mimése e da alteridade (inscritas na máscara) e da poesia dramática como encenação do imaginário arquetipal, o caminho que conduz a cultura teatral do ocidente do ritual dionisiaco à tragédia e ao "drama lutuoso", sublinhando o facto de uma laicização de o drama abrir espaço ao combate entre filosofia e poesia o qual irá, como se diz, "operar a passagem de uma catarse de proveniência religiosa para uma ascese próxima da investigação filosófica".

Para além de retomar aspectos fundamentais de estética teatral, esta introdução serve, sobretudo, para: a) mergulhar o leitor na tese, isto é, na ideia de que o teatro é lugar de revisitação dos arquétipos sob a forma das tais máscaras nigromantes, assim como lugar de manifestação de um "verbo paciente" (p. 49), metáfora do texto que sofre a sua condição de ter de aguardar a cena (o que sabemos não poder, todavia, ser metáfora para todo o teatro...); b) provar que realizar um outro teatro (reconhecivel em parte no drama lutuoso, mas também no drama estático simbolista) terá sido importante impulso/pulsão da escrita patriciana, só perceptível se reconhecermos nela a presença do trabalho filosófico empreendido desde a Antiguidade à volta da noção de drama (representação de acções humanas no presente e ao vivo).

Dai ser colocada a hipótese de a escrita de Patricio incorporar e levar quase às últimas consequências a aproximação entre drama e logos, aproximação que se foi construindo, no ocidente, pela necessidade de fixar o indizivel (do corpo) em dito, mas também de "empurrar o raciocínio para mais longe do que os freios conceptuais o autorizariam", nas palavras de Armando Rosa (p. 73).

Nas referidas três partes nucleares, segue o A. um mesmo modo de exposição, bem revelador do procedimento escolhido e das perspectivas, quanto a mim acertadas e produtivas, que elegeu para estudar o teatro escrito de Patrício: uma perspectiva filosófica, temática e simbólica; uma perspectiva intertextual e histórico-cultural; uma perspectiva histórico-literária, incluindo-se aqui, obviamente, a história da literatura dramática portuguesa.

Assim, em três momentos, o leitor acompanha, através do universo histórico e cultural contextualizador específico de cada texto, uma macro-leitura que retira aquele do seu isolamento e the confere um alcance alargado no quadro das práticas humanas, passando em seguida ao espaço da micro-leitura que identifica o funcionamento singularizante de aspectos literários (poetico-retóricos), mas também simbólicos, temáticos e arquetípicos (tão caros a Armando Rosa), atravessando ainda um território intermédio no qual, e no âmbito restrito da literatura e dos movimentos literários coevos, os modelos poéticos em vigor são convocados para fazer ressaltar a singularidade de uma poética de autor (dai serem convocados outros textos, quer de Patrício, quer de autores nacionais e estrangeiros).

Apesar de esta minha descrição sugerir uma separação, um faseamento, passiveis de conferir uma certa desconexão ao escrito, tal não acontece. De facto, Armando Rosa realiza a proeza de ligar de um modo coerente e eficaz os diversos planos de análise e de propor interpretações parcelares que vão construindo a sua leitura, ao mesmo tempo que produzem um efeito amplificador sobre a obra de Patrício (e creio ser esta a palavra certa para designar a descoberta por parte do leitor de uma poiesis singular patriciana). Quase diria que a escrita de Patrício surge transfigurada pela leitura-escrita de Armando Rosa o que constitui, sem dúvida, um dos méritos do seu estudo. Exemplo do que acabo de afirmar é o modo como convoca em Pedro, o cru o pensamento saudosista para ler a dimensão filosófica do teatro do seu autor.

Mas a questão que considero mais interessante para a análise da escrita de Patrício e um contributo para os estudos de teatro, prende-se com a teatralização da palavra dramática (para usar a formulação de Armando Rosa). Nela emerge a dimensão invocativa, do pathos traduzido em acção para ser seguida no tempo e no espaço, que é evidentemente inseparável do programa filosófico manifestado nessa invocação (relação homem/divindade, vida/morte, corpo/espirito, aprendizagem para a morte, busca do conhecimento etc.).

Assim, quando na Introdução, muito oportunamente, o A. inaugura um dos fios condutores da sua análise a palavra como espectáculo - que irá retomando na análise dos textos e desembocará na Conclusão, toca o aspecto nuclear da concepção de teatro em Patrício. Revela como ao mesmo tempo que recupera e radicaliza a tradição ocidental do drama logocentrado, Patrício descobre a via para a criação do seu próprio programa: inventar um drama que expõe a sua literariedade, que mostra o investimento poético na criação de uma linguagem "insoluble", como escreveu Antoine Vitez a propósito de Claudel. E é também isso que Armando Rosa afirma acerca desta dramaturgia quando escreve que ela "faz do palco o território eleito para a revelação quasi-religiosa da poesia". Esta questão perpassa também na ideia de um "papel teatral da linguagem verbal" e na sombra presente de Artaud, se bem que possamos interrogar ou mesmo duvidar dessas afinidades imediatas.

Ao longo da análise temática dos textos de Patrício, Armando Rosa voltará a esta questão central da teatralidade e da "encenabilidade": quando aproxima 0 fim de Pátria de Guerra Junqueiro a propósito do discurso directo e da forma dialogal; quando "encena" a figura do Desconhecido à luz do teatro épico de Brecht; quando se debruça sobre uma certa recusa da materialidade cénica nos textos simbolistas; quando procura analisar a função das didascálias no exercício de imaginação cénica; quando aborda a narratividade como aparente negação da performatividade; quando adivinha concretizações cénicas para certos traços caracterizadores das personagens; quando procura tornar visivel a palavra enquanto espectáculo de si mesma, através dos jogos ritmicoprosódicos que analisa. 
Salto inexoravelmente para a Conclusão ( "A palavra cénica - a herança estética do teatro patriciano") nela destacando ainda o tópico da dramaticidade vs teatralidade presente na palavra cénica que Armando Rosa define como uma "palavra-actriz" que "representa autónoma e teatralmente por si mesma" (p. 519).

Depois de propor uma interpretação para o silenciamento do teatro escrito de Patrício baseada no desfasamento entre este e o momento histórico-cultural que se prolongou até aos anos 70 do século passado, identificando - com perspicácia e cruzando múltiplos e variados discursos sobre a obra - as razões para o desprezo ou desapreço por esta escrita, Armando Rosa arrisca uma explicação para o desencontro entre os textos e o palco. A palavra cénica solicitaria do espectador uma disponibilidade diversa da que lhe é exigida pelo drama tal como a tradição aristotélica o foi escrevendo e os palcos o foram encenando.

Creio que poderíamos acrescentar a este argumento dois outros: 1) que o leitor tende a não distinguir na letra do texto dramaticidade ou qualidade dramática de teatralidade ou factor teatral, valorizando então o lirismo, a "poesia na linguagem do drama", como afirma Armando Rosa; 2) que na impossibilidade de identificar facilmente o factor teatral inscrito no texto - presente na palavra posta em cena, exposta no seu eficaz poder evocativo e no seu envolvimento rítmico, no grau de performatividade do discurso - o leitor refugia-se na densidade das imagens e dos simbolos e, na melhor das hipóteses, reconhece nesta dramaturgia os lugares-comuns do simbolismo, como sejam o da enunciação do indizivel, a crença numa linguagem universal, das origens, o primado da intemporalidade que revela uma visão metafisica e teológica da linguagem.

Mas à questão omnipresente e de fundo da teatralidade dos textos que António Patrício escreveu no interior de um modelo genológico (o dramático) responde Armando Rosa através do cruzamento intertextual e através do reconhecimento de um teatro virtual nas letras do texto.

Creio que pretendeu e conseguiu realizar os seus objectivos: sem deixar de reconhecer e sublinhar na escrita de Patrício o cruzamento dos modelos estético-literários com os quais o autor se confrontou e que incorporou transfigurando-os, propõe uma leitura coerente de cada texto e do percurso de escrita de texto para texto com o intuito, plenamente realizado, de provar a singularidade da obra; sem ceder ao facilitismo de colar ou aplicar teorias estranhas à obra, se bem que recorrendo às que reconhece como dela estando próximas (de Platão a Schopenhauer), consegue tornar evidente a dimensão filosófica do programa dramatúrgico de Patrício, conferindo-Ihe amplitude e espessura insuspeitadas; prova, finalmente, que só dando a ler as determinações verbais e não verbais (a interacção socio-política, por exemplo) que acompanham a textualização (e, no que toca ao teatro, a sua realização cénica) podemos ultrapassar as eternas dicotomias do texto representável/irrepresentável, teatral/não teatral, para ler/para representar que reproduzem a perenidade de uma ideia supostamente universal, ahistórica de teatro. Tudo isto conservando-se fiel às matrizes críticas da sua eleição: a mitopoética e a simbólica, às quais juntou a indagação filosófica que uma leitura de tão singular obra não dispensa. 